\title{
Characterization of Physiological and Biochemical Factors Associated with Postharvest Water Loss in Ripe Pepper Fruit during Storage
}

\author{
Maalekuu Kissinger, Sharon Tuvia-Alkalai, Yavin Shalom, and Elazar Fallik ${ }^{1}$ \\ Department of Postharvest Science of Fresh Produce, ARO, The Volcani Centre, 50250 Bet-Dagan, \\ Israel
}

\author{
Yonatan Elkind \\ Institute of Plant Sciences, Faculty of Agricultural, Food and Environmental Sciences, Rehovot, The \\ Hebrew University of Jerusalem, Israel

\begin{abstract}
Matthew A. Jenks and Mark S. Goodwin
Department of Horticulture and Landscape Architecture, Purdue University, West Lafayette, IN 47907
\end{abstract}

\begin{abstract}
Additional IndeX words. Capsicum annuum, cuticle, cutin, fruit characteristics, ion leakage, lipoxygenase activity, pepper, postharvest, wax

Abstract. Fruit of pepper (Capsicum annuum L.) is hollow by nature, which limits its water reservoir capacity, and as such, small amounts of water loss result in loss of freshness and firmness, which reduce fruit quality, shelf life, and market value. In order to understand the basis for water loss from fruit, 10 pepper accessions with wide variation in water loss rate were used to study physiological and biochemical factors associated with postharvest water loss in ripe pepper fruit during storage. Postharvest water loss rate in ripe pepper fruit stored at $20^{\circ} \mathrm{C}$, and $85 \%$ relative humidity, was found to be associated with cell membrane ion leakage, lipoxygenase activity, and total cuticular wax amount. Total cuticular wax amounts were highest in the high-water-loss pepper fruit, and lowest in the low-water-loss fruit. However, total cuticle amount (isolated enzymatically and quantified gravimetrically), total cutin monomer amount, and the amount of individual cutin monomer and wax constituents (determined using gas chromatography mass spectrometry) indicated no direct association with postharvest water loss rates. Fruit fresh weight, pericarp weight, pericarp surface area, pericarp thickness, initial water content, and dry matter were highly associated with each other, but less so with water loss rate. Fruit of accessions displaying high fruit water loss rate matured and ripened earlier than fruit of accessions displaying low-water-loss rate. Cell membrane ion leakage and lipoxygenase activity were higher after storage than immediately after harvest. Pepper fruit total cuticle wax amount, lipoxygenase activity, and cell membrane ion leakage were directly related to postharvest water loss rate in pepper fruit during storage.
\end{abstract}

The postharvest loss of water by many horticultural products used for the fresh market, such as fruit, vegetables, and cut flowers, causes a loss in the product's fresh, firm, and glossy state, and a shortening of shelf-life, resulting in loss of economic value and income. Excessive water loss from eggplant (Solanum melongena L.) fruit, for example, causes softening, shriveling, loss of peel gloss, and calyx browning due to dehydration (Diaz-Perez, 1998). Lownds et al. (1993) observed that the loss in relative water content of pepper fruit increased linearly with storage time, and differed for each cultivar examined. Pepper fruit water loss rate was shown to correlate positively with initial water content and ratio of surface area to volume, but was negatively correlated with surface area. A direct relationship also existed between pepper fruit softening and water loss, since softening followed a pattern similar to water loss at each storage temperature (Lownds et al., 1994). In another study, water loss from pepper fruit in

Received for publication 29 Nov. 2004. Accepted for publication 3 Apr. 2005. This research was funded by the Chief Scientist of the Israeli Ministry of Agriculture and Rural Development, No. 406-0769-04. Contribution from the Agricultural Research Organization, the Volcani Center, Bet Dagan, Israel, No. 428/05. We are grateful to I.W. Boukema, of Plant Research International, Wageningen, Holland, who supplied the plant materials used in this study to the Hebrew Univ. of Jerusalem. We thank Susan Lurie for the critical review of the manuscript.

'To whom reprint requests should be addressed; e-mail: efallik@volcani.agri. gov.il
New Mexico resulted in loss of quality and limited fruit export to distant markets (Watada et al., 1987).

The lipoidal cuticle layer (composed primarily of waxes and cutin) covering the fruit surface, is thought to provide a major hydrophobic barrier to fruit water loss (Goodwin and Jenks, 2005). In studies of over 60 plant species, the maximum barrier properties of plant cuticles far exceed that of synthetic polymeric films of equal thickness (Riederer and Schreiber, 2001). However, the water permeability of fruit cuticles has not been correlated to the thickness of the cuticle or to the total wax amount. For example, Vega et al. (1991) found no relationship between cuticle structural features and weight loss of blueberry (Vaccinium corymbosum L.) fruit during storage. Notwithstanding, other studies provide evidence that certain characteristics of cuticular lipids play a major role in regulating postharvest water loss (Banaras et al., 1988; El-Otmani and Coggins, 1985; Lownds et al., 1993; Maalekuu et al., 2003) via their interactions with polar diffusion pathways in the cutin framework of the cuticle membrane, and via their role in forming impermeable crystalline regions that resist water flux through the cuticle (Baur et al., 1999; Goodwin and Jenks, 2005).

Coupled with the wilting and dehydration of horticultural produce during storage, deterioration of plant tissues is also of importance to food and horticultural scientists. Evidence gathered 
to date supports membrane damage as the key event leading to a cascade of biochemical reactions culminating in tissue deterioration and economic loss. Biophysical changes in membrane lipids and enzymatic and nonenzymatic lipid peroxidation led to altered membrane properties and resulted in ion leakage and cellular decompartmentation (Lacan and Baccou, 1996; Marangoni et al., 1996). Water stress has also been associated with increased cell membrane ion leakage from plant products (Leopold et al., 1981). Lipoxygenase, among other enzymes that change membrane composition, has been implicated in membrane degradation during fruit ripening and senescence (Luo, 1994; Rogiers-Suzy et al., 1998). Lipoxygenase activity has been found to increase in tomato (Lycopersicon esculentum Mill.) fruit during ripening and senescence (Ealing, 1994) resulting in a decrease in product quality and commercial value (Minguez-Mosquera et al., 1994).

Based on these reports, fruit cuticle, cuticular wax, membrane ion leakage, and lipoxygenase enzyme activity are likely major determinants of postharvest water loss. To the best of our knowledge, these four parameters have not been directly compared for possible relationships to postharvest water loss rate in pepper fruit during storage. The goal of this study was to characterize morphological, physiological, and biochemical properties of ripe pepper fruit during storage to provide information on associations between cuticle properties, membrane integrity, lipoxygenase activity, and pepper fruit water loss rate.

\section{Materials and Methods}

Plant materials. Ten pepper cultivar types (Table 1), selected from germplasm representing over 26 countries, and including pungent and nonpungent, and different fruit size types, were obtained by the Hebrew Univ., Plant Breeding and Genetics laboratory. These were grown in a protected net house in the Arava Valley (southern Israel) under cool climatic conditions. The soil condition was well drained and sandy, and drip irrigation was used to apply water to plants. Cultural practices applied, such as land preparation, planting, and plant protection for the crop were as is the standard in this area. Facilities met the requirements for export production. The experimental design used was the randomized complete-block design. Ten plants from each cultivar type were transplanted to a plot in two blocks. Data was

collected from six fruit per cultivar type in each block and a total of three harvests made in the season. To simulate normal harvest and storage, fruit of $75 \%$ to $80 \%$ red coloration were selected as the standard time point to harvest fruit for subsequent treatment and analysis. Experimental procedures applied at each harvest were the same. All data were subjected to statistical analysis using JMP statistical analysis software (SAS Institute, Cary, N.C.) (Sall et al., 2001). The Fit Model was used to estimate variance and multiple regression used to estimate correlation coefficient between parameters studied. The least mean square values were used to estimate correlation coefficient values between the parameters of interest.

WATER LOSS RATE PARAMETERS. Water loss was measured from red ripe fruit stored for up to $5 \mathrm{~d}$ at $20{ }^{\circ} \mathrm{C}$ and $80 \%$ to $85 \%$ relative humidity $(\mathrm{RH})$. Fruit water loss rate (WLR) was determined as fruit absolute water loss (AWL) in milligrams per fruit pericarp surface area (PSA) in square centimeters over time $(\mathrm{H})$ in hours expressed as follows: WLR $=$ AWL/PSA/H. Fruit pericarp surface area (PSA) was determined using the disk weight (DWT), disk area (DA), and pericarp weight (PWT) relationship as follows: $\mathrm{PSA}=\mathrm{DA} \times \mathrm{PWT} / \mathrm{DWT}$. A cork borer $(14 \mathrm{~mm}$ diameter $)$ was used to punch three disks per fruit from the pericarp, weighed and oven dried for $24 \mathrm{~h}$ at $65^{\circ} \mathrm{C}$ to determine water content and dry matter expressed as percentage of fresh disk weight.

Membrane InTEGRITY. Membrane ion leakage was determined using the method of Knowles et al. (2001) with some modifications. Briefly, 10 disks (14 mm diameter) per cultivar were incubated in 25-mL double-distilled deionized water at 3-, 6-, 12-, 30-, and 60 -min intervals and conductivity measured and expressed as a percentage of total electrolyte. Total electrolyte was determined by freezing samples overnight after taking all readings (from 3 to $60 \mathrm{~min}$ ). Samples were then thawed, boiled for $15 \mathrm{~min}$, and conductivity measured. A radiometer conductometer (El-Hama Instruments, El-Hama, Israel) was used to measure membrane ion leakage.

LIPOXYGENASE ASSAY. Lipoxygenase activity was determined as described by Minguez-Mosquera et al. (1993) with some modifications. Pepper pericarp tissue $(15 \mathrm{~g})$ was homogenized in $30-\mathrm{mL}$ ice-cold phosphate buffer $(0.05 \mathrm{M}, \mathrm{pH} 7.0)$ for $1 \mathrm{~min}$ using a Turrax homogenizer (Kinematica, Luzern, Switzerland). The homogenate was centrifuged at $10,000 g_{n}$ for $15 \mathrm{~min}$ at 4 ${ }^{\circ} \mathrm{C}$ and filtered. The substrate was prepared by solubilizing $0.5 \mathrm{~g}$

Table 1. Means of water loss rate (WLR), membrane ion leakage (EL), lipoxygenase activity (LOX), total cuticle amount determined gravimetrically (CU), and total cuticular wax amount determined gravimetrically $(\mathrm{CW})$, of the fruit of 10 selected pepper cultivars after $5 \mathrm{~d}$ storage at $20{ }^{\circ} \mathrm{C}$ and $85 \%$ relative humidity.

\begin{tabular}{|c|c|c|c|c|c|}
\hline Cultivar & $\begin{array}{c}\text { WLR } \\
\left(\mathrm{mg} \cdot \mathrm{cm}^{-2} \cdot \mathrm{h}^{-1}\right)\end{array}$ & $\begin{array}{c}\text { EL } \\
(\% \text { total } \\
\text { electrolyte) }\end{array}$ & $\begin{array}{c}\mathrm{LOX} \\
\left(\mathrm{U} \cdot \mathrm{mg}^{-1} \cdot \mathrm{min}^{-1}\right)\end{array}$ & $\begin{array}{c}\mathrm{CU} \\
\left(\mathrm{mg} \cdot \mathrm{cm}^{-2}\right)\end{array}$ & $\begin{array}{c}\mathrm{CW} \\
\left(\mu \mathrm{g} \cdot \mathrm{cm}^{-2}\right)\end{array}$ \\
\hline il-57 & $0.78 \mathrm{~b}^{\mathrm{z}}$ & $7.28 \mathrm{c}$ & $0.77 \mathrm{ab}$ & $1.74 \mathrm{bcd}$ & $3.14 \mathrm{c}$ \\
\hline il-58 & $0.70 \mathrm{bc}$ & $7.33 \mathrm{c}$ & $0.56 \mathrm{bc}$ & $2.65 \mathrm{~b}$ & $3.49 \mathrm{bc}$ \\
\hline il-60 & $0.67 \mathrm{bcd}$ & $7.18 \mathrm{c}$ & $0.57 \mathrm{bc}$ & $1.36 \mathrm{~cd}$ & $3.64 \mathrm{bc}$ \\
\hline il-78 & $0.54 \mathrm{~d}$ & $5.89 \mathrm{~d}$ & $0.45 \mathrm{c}$ & $1.64 \mathrm{bcd}$ & $5.82 \mathrm{abc}$ \\
\hline il-80 & $1.27 \mathrm{a}$ & $9.71 \mathrm{a}$ & $0.80 \mathrm{ab}$ & $1.07 \mathrm{~d}$ & $8.47 \mathrm{a}$ \\
\hline il-93 & $0.64 \mathrm{bcd}$ & $6.8 \mathrm{~cd}$ & $0.75 \mathrm{~b}$ & $2.34 \mathrm{~b}$ & $5.36 \mathrm{abc}$ \\
\hline il-100 & $1.16 \mathrm{a}$ & $8.72 \mathrm{~b}$ & $0.79 \mathrm{ab}$ & $4.70 \mathrm{a}$ & $4.80 \mathrm{abc}$ \\
\hline il-107 & $1.24 \mathrm{a}$ & $8.46 \mathrm{~b}$ & $0.92 \mathrm{a}$ & $1.39 \mathrm{~cd}$ & $6.84 \mathrm{ab}$ \\
\hline il-152 & $0.61 \mathrm{~cd}$ & $6.91 \mathrm{~cd}$ & $0.35 \mathrm{c}$ & $1.93 \mathrm{bc}$ & $3.37 \mathrm{bc}$ \\
\hline il-153 & $0.62 \mathrm{~cd}$ & $6.73 \mathrm{~cd}$ & $0.62 \mathrm{~b}$ & $2.33 \mathrm{~b}$ & $4.77 \mathrm{abc}$ \\
\hline$P$ value & 0.0001 & 0.0001 & 0.0001 & 0.001 & 0.001 \\
\hline
\end{tabular}

zValues in columns not connected by the same letter are significantly different. $P \leq 0.01$, according to Tukey-Kramer honestly significant difference. linoleic acid (Sigma, Rehovot, Israel) with $0.5 \mathrm{~g}$ Tween 20 in deionized and deoxygenated water and final volume brought to $25 \mathrm{~mL}$. Turbidity was cleared with few drops of $2 \mathrm{~N} \mathrm{NaOH}$. The crude extract $(40 \mu \mathrm{L})$ was reacted with the substrate $(20 \mu \mathrm{L})$ in a spectrophotometer cuvette containing $3 \mathrm{~mL}$ phosphate buffer $0.2 \mathrm{M}$, at $\mathrm{pH} 6.5$ and the absorbance measured at 234 $\mathrm{nm}$ at 6-s intervals for $1 \mathrm{~min}$ using a recording spectrophotometer. The rate of formation of conjugated diene reaction products, measured as an increase in $\mathrm{A}_{234 \mathrm{~nm}}$, was used to calculate specific enzyme activity per unit of time, defined as unit of activity (or moles of products formed) per milligram protein in $1 \mathrm{~min}$.

Wax extraction. Total hexane soluble cuticular waxes and total cuticle [cuticle membrane plus waxes (desiccator-dried)] were extracted and quantified for each of the 10 selected cultivars. More detailed analysis 
of total wax classes and individual constituents, and total cutin monomers, were performed for four cultivars representing the high-, medium-, and low-water-loss lines from among the 10 selected cultivars. The cuticular waxes were extracted by rinsing whole fruit in hexane (GC grade) for $45 \mathrm{~s}$, evaporating the hexane, and then quantified both gravimetrically and with a gas chromatography-mass spectrometry (GC-MS), with internal standards and multilevel calibration according to methods of Jenks et al. (1995, 2001).

Cuticle AnAlysis. The methods of Norris and Bucovac (1968) and Xiao et al. (2004) were modified and used for total cuticle extraction and cutin monomer analysis, respectively. Briefly, cuticle membrane was isolated with a mixed pectinase $2.0 \%(\mathrm{w} / \mathrm{v})$ and cellulase $0.1 \%$ (w/v) (i.e., $0.2 \mathrm{M}$ acetate buffer plus 1100 and 525 units of pectinase and cellulose respectively) solution buffered at $\mathrm{pH} 3.8$, refluxed with chloroform/methanol to remove soluble waxes, and the remaining cutin depolymerized for analysis by GC-MS.All cutin monomers were identified from electron impact mass spectroscopy of the methyl ester trimethylsilylation derivatives on the basis of published spectra (Eglinton and Hunneman, 1968; Holloway, 1982), retention indexes (Holloway, 1984), and retention times of the authentic standards hexadecanoic acid hexadecane-1,16-dioic acid, 16-hydroxy hexadecanoic acid, and octadecanoic acid.

\section{Results}

Analysis of WATER LOSS RATE. The 10 pepper cultivar types used in this study (Table 1) were chosen to represent a wide variation in water loss rates, with all subsequent analyses being made using fruit at the $75 \%$ to $80 \%$ red ripe stage as a representative harvest standard. Selections were based on daily weight loss of these red ripe fruit over a period of time, and expressed as water loss rate relative to fruit surface area. Commercial waxes were used to coat, in various combinations, the pericarp, stalk, and calyx surfaces to reveal that most water loss from pepper fruit occurred through the pericarp surface, with very little to insignificant amounts of water loss occurring from the stalk or calyx (data not shown). Besides these significant cultivar differences in mean water loss rate, statistically significant differences were also observed for membrane ion leakage, lipoxygenase activity, fruit cuticle weight, cutin amount, wax amount, and the proportional amounts of individual cutin monomers and wax constituents (Tables 1, 3, 4, 5).

There were significant differences between harvests 1,2 , and 3 in red ripe fruit water loss rate $5 \mathrm{~d}$ after storage, however, the low- and high-water-loss cultivars retained their water loss relationships to one another. On average, fruit of harvest 1 lost more water $\left(0.84 \mathrm{mg} \cdot \mathrm{cm}^{-2} \cdot \mathrm{h}^{-1}\right)$ than that of harvest $2\left(0.82 \mathrm{mg} \cdot \mathrm{cm}^{-2} \cdot \mathrm{h}^{-1}\right)$ and harvest $3\left(0.71 \mathrm{mg} \cdot \mathrm{cm}^{-2} \cdot \mathrm{h}^{-1}\right)$. Since differences between harvests were relatively minor, and cultivar relationships generally remained the same, more detailed analyses are presented for total wax classes and constituents and cutin monomers of fruit from the first harvest only.

The fruit ( $75 \%$ to $80 \%$ red ripe) of 'il-80' and 'il-107' after $5 \mathrm{~d}$ storage had the highest water loss rate $\left(1.27\right.$ and $\left.1.24 \mathrm{mg} \cdot \mathrm{cm}^{-2} \cdot \mathrm{h}^{-1}\right)$, while 'il-78' and 'il-152' had the lowest water loss rates $(0.54$ and $\left.0.61 \mathrm{mg} \cdot \mathrm{cm}^{-2} \cdot \mathrm{h}^{-1}\right)($ Table 1$)$. Analysis of variance indicated significant interaction effect on water loss rate between cultivar types and harvest $(P \leq 0.001)$. Interestingly, fruit from high-waterloss cultivars il-80 and il-107 ripened earlier than other cultivars by 3 weeks and 2 weeks respectively, while low-water-loss fruit from 'il-78' and 'il-152' were the last to reach the red ripe stage (up to 2 weeks later than other cultivars).

MEMBRANE INTEGRITY AND WATER LOSS. Membrane ion leakage results indicated significant differences among cultivars. Cultivars il-80, il-100, and il-107 recorded the highest ion leakage values $(9.71 \%, 8.72 \%$, and $8.46 \%$ of total electrolytes, respectively); while cultivars il-78, il-93, il-153, and il-152 recorded the lowest ion leakage $(5.89 \%, 6.8 \%, 6.73 \%$, and $6.91 \%$ of total electrolytes, respectively) (Table 1). There existed a strong association (0.95) between water loss rate and membrane ion leakage (Table 2).

Trend OF LiPOXYgenase ACTIVITY. Lipoxygenase activity followed a pattern similar to that of water loss rate and cell membrane ion leakage (Table 1). Cultivars il-107, il-80, il-100, and il-57 had high lipoxygenase activity $(0.92,0.80,0.79$, and 0.77 $\mathrm{U} \cdot \mathrm{mg}^{-1} \cdot \mathrm{min}^{-1}$, respectively); while cultivars il-152, il-78, il-58, and il-60 showed low activity $\left(0.35,0.45,0.56\right.$, and $0.57 \mathrm{U} \cdot \mathrm{mg}^{-1} \cdot \mathrm{min}^{-1}$, respectively). Lipoxygenase activity was positively associated with water loss rate (0.78) and cell membrane ion leakage (0.68) (Table 2). Cell membrane ion leakage and lipoxygenase activity measured immediately after harvest was much lower than after storage (data not shown).

CUTICLE PROPERTIES AND WATER LOSS RATE RELATIONSHIP. There were variations among pepper cultivars in fruit cuticle lipid (wax and cutin) amounts and composition (Tables 1, 3, 4, 5). Cutan, a nondepolymerizable component in the cuticle membranes of many species, was also present as a very minor component in pepper fruit cuticles (data not shown). Due to its low abundance, it was not examined further in this study. Cultivars il-80 and il-107 that had the highest water loss rates, had the lowest total cuticle amounts per area (1.1 and $1.4 \mathrm{mg} \cdot \mathrm{cm}^{-2}$, respectively), whereas cultivars il-78 and il-152 that had the lowest water loss rates, had much higher cuticle amounts ( 1.6 and $1.9 \mathrm{mg} \cdot \mathrm{cm}^{-2}$, respectively) (Table $1)$. The highest cuticle amounts were recorded for 'il-100' (4.7 $\left.\mathrm{mg} \cdot \mathrm{cm}^{-2}\right)$ and 'il-58' $\left(2.7 \mathrm{mg} \cdot \mathrm{cm}^{-2}\right)$, two lines showing quite rapid water loss (Table 1). From these observations, we can conclude that pepper fruit cuticle amount was not associated with water loss rate (0.1) (Table 2). Neither was cuticle amount associated with cell membrane ion leakage $(0.09)$ or lipoxygenase activity (0.09) during storage (Table 2).

Analysis of pepper fruit cutin monomer constituents in four representative cultivars (which covered the high-, medium-, and low-water-loss groups of the 10 lines) indicated that 9(10),16dihydroxy hexadecanoic acid was the major monomer in pepper fruit. This component in 'il-58' cutin was nearly twice as high as the same component in 'il-60' fruit, the next most cutin-rich pepper genotype (Table 3). Interestingly, however, 'il-58' was classified as a medium-water-loss-rate line, and as such, neither the total amount of cutin monomers nor their relative proportions could be shown in this study to have an association with variations in pepper fruit water loss rates (Table 3).

Table 2. Correlation coefficient values between water loss rate (WLR), cellular membrane ion (electrolyte) leakage (EL), total cuticular wax amount determined gravimetrically $(\mathrm{CW})$, total cuticle amount determined gravimetrically (CU), and lipoxygenase activity (LOX) of fruit of 10 pepper cultivars after $5 \mathrm{~d}$ storage at $20{ }^{\circ} \mathrm{C}$ and $85 \%$ relative humidity.

\begin{tabular}{lcccc}
\hline & EL & CW & CU & LOX \\
\hline WLR & 0.95 & 0.63 & 0.10 & 0.78 \\
EL & & 0.56 & 0.09 & 0.68 \\
CW & & & -0.29 & 0.50 \\
CU & & & & 0.09 \\
\hline
\end{tabular}


Table 3. Total amounts of each cutin monomer of the pepper cuticle from four representative cultivars ('il-60', 'il-78', 'il-58', and 'il-80') after $5 \mathrm{~d}$ storage at $20^{\circ} \mathrm{C}$ and $85 \%$ relative humidity. Isomers are shown in parentheses.

\begin{tabular}{|c|c|c|c|c|}
\hline \multirow[b]{5}{*}{ Cutin constituents } & \multicolumn{4}{|c|}{ Cultivar } \\
\hline & il-60 & il-78 & il-58 & il-80 \\
\hline & \multicolumn{4}{|c|}{ Water-loss-rate classification ${ }^{z}$} \\
\hline & Low & Low & Medium & High \\
\hline & \multicolumn{4}{|c|}{ Cutin amount $\left(\mu \mathrm{g} \cdot \mathrm{cm}^{-2}\right)$} \\
\hline Methyl $m$-coumaric acid & 12.8 & 12.3 & 36.8 & 4.7 \\
\hline Hexadecanoic acid & 0.7 & 0.9 & 1.7 & 0.6 \\
\hline 16-hydroxy hexadecanoic acid & 11.6 & 9.7 & 32.5 & 5.5 \\
\hline 16-hydroxy-9(10)-oxo hexadecanoic acid & 6.8 & 3.9 & 30.5 & 5.8 \\
\hline $9(10), 16$-dihydroxy hexadecanoic acid & 312.2 & 232.4 & 618.2 & 247.4 \\
\hline Hexadecane-1, 16-dioic acid & 3.7 & 3.0 & 7.0 & 1.5 \\
\hline 7(8)-hydroxy hexadecane-1,16-dioic acid & 10.2 & 7.8 & 13.3 & 9.0 \\
\hline Octadecanoic acid & 0.6 & 0.2 & 0.8 & 0.3 \\
\hline 18-hydroxy octadecanoic acid & 4.7 & 6.4 & 8.1 & 5.5 \\
\hline 9(10), 18-dihydroxy octadecanoic acid & 10.5 & 8.1 & 31.5 & 11.0 \\
\hline $\begin{array}{l}\text { 9-epoxy-18-hydroxy octadecanoic acid }{ }^{\mathrm{x}} \\
\text { plus } 9,12,18 \text {-trihydroxy octadecenoic acid } \mathrm{x}, \mathrm{y}\end{array}$ & 34.1 & 26.5 & 56.1 & 36.5 \\
\hline 9-epoxy-18-hydroxy octadecenoic acidy & 58.9 & 24.5 & 104.4 & 50.0 \\
\hline 9,10,18-trihydroxy octadecanoic acid & 8.3 & 5.5 & 14.4 & 7.1 \\
\hline Total $^{\mathrm{w}}$ & 475.0 & 341.2 & 955.2 & 384.8 \\
\hline
\end{tabular}

${ }^{2}$ Cultivars for detailed cuticular lipid analysis were selected to represent a broad range in water loss rate classification based on Table 1.

yPosition of double bond not determined.

x9-epoxy-18-hydroxy octadecanoic acid and 9,12,18-trihydroxy octadecenoic acid co-elute on HP-1 column.

wStandard deviations for total amount of cutin monomers on 'il-60', 'il-78', 'il-58', and 'il80 ' were $71.2,107.6,170.8$, and 52.6, respectively. The standard deviations for individual monomers were comparable to deviations of the total cutin monomers (data not shown).

Table 4. Total amounts of pepper fruit cuticular wax classes on four pepper cultivars ('il60', 'il-78', 'il-58', and 'il-80') determined using GC-MS after $5 \mathrm{~d}$ storage at $20^{\circ} \mathrm{C}$ and $85 \%$ relative humidity.

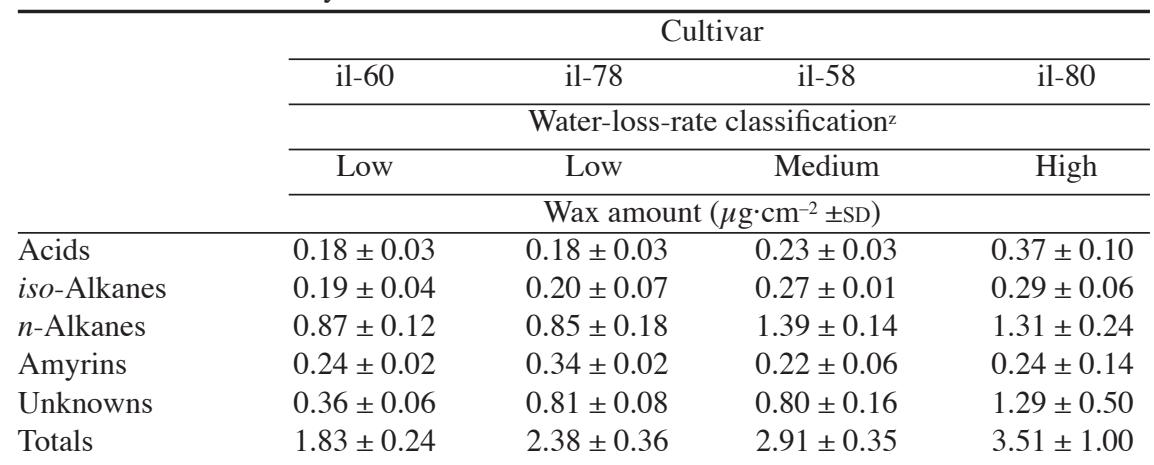

${ }^{2}$ Cultivars for detailed cuticular lipid analysis were selected to represent a broad range in water loss rate classification based on Table 1 .

Cuticular WaX, WATER loss Rate, MEMbrane integrity, AND LOX ACTIVITY RELATIONSHIPS. Cuticular wax amount (determined gravimetrically) was significantly different among cultivars, with low-water-loss cultivars il-152 and il-78 having low cuticle wax amounts (3.37 and $5.82 \mu \mathrm{g} \cdot \mathrm{cm}^{-2}$, respectively), and with highwater-loss cultivars il-80, il-107, and il-100 having high cuticle wax content $\left(8.47,6.84\right.$, and $4.80 \mu \mathrm{g} \cdot \mathrm{cm}^{-2}$, respectively) (Table 1). Wax amounts determined gravimetrically were directly associated with water loss rate $(0.63)$, cell membrane ion leakage (0.56), and lipoxygenase activity (0.50) (Table 2$)$. Analysis of the amount of total wax in each class (Table 4) and individual wax constituents (Table 5) of the four representative cultivars were comparable except that 'il-80' had proportionally more unknown (undetermined) compounds (preliminary mass spectral analysis suggested many of these were triterpenoids). Results indicated that $n$-alkanes were the major aliphatic constituents, with amyrins being the major aromatic constituent (Table 4 ), and the $\mathrm{C}_{31}$ alkane the predominant single constitituent (Table 5). Significant deposits of methyl-branched alkanes $\left(\mathrm{C}_{27}\right.$ iso-alkane, 2-methyl $\mathrm{C}_{26} ; \mathrm{C}_{29}$ iso-alkane, 2-methyl $\mathrm{C}_{28} ; \mathrm{C}_{31}$ iso-alkane, 2-methyl $\mathrm{C}_{30}$; and $\mathrm{C}_{33}$ iso-alkane, 2-methyl $\mathrm{C}_{32}$ ) were also present on pepper fruit (Table 5). A direct association between wax composition and water loss rate was not observed. Whether the unknown compounds in 'il-80' somehow explain the very high water loss for 'il-80' fruit is still unknown.

AtTributes OF FRUIT PHYSICAL CHARACTERISTICS. The physical properties of the fruit of these 10 cultivars, such as fruit fresh weight, pericarp weight, pericarp surface area, pericarp thickness, initial water content, and dry matter content were significantly different among cultivars (Table 6). These parameters showed close interdependent relationships, however, associations between these parameters and water loss rate were moderate except for pericarp thickness, which showed no association at all (0.01). There were negative correlations between water loss rate and fruit fresh weight $(-0.41)$, fruit pericarp weight $(-0.41)$, pericarp surface area $(-0.52)$, initial water content $(-0.41)$, but a positive correlation with dry matter content (0.51). Associations between fruit fresh weight, fruit pericarp weight, pericarp surface area, pericarp thickness, initial water content, and dry matter content were very high (Table 7).

\section{Discussion}

Compared to most fruit, fruit of pepper are very susceptible to injury by postharvest water loss. This may be because pepper is a hollow fruit and has limited ability to store large volumes of water for long periods. Fruit water loss can cause severe desiccation, a condition that often results in a complete loss, such as when the produce is no longer saleable (Robinson et al., 1975). Maalekuu et al. (2004) reported that the effect of weight loss in commercial pepper cultivars is damage to fruit appearance and subsequent loss of fruit market value. Similar to our results presented here, studies by Maalekuu et al. (2004) showed strong correlations between weight (water) loss rates and both general fruit appearance $(-0.69)$ and fruit firmness (0.93), and significant interactions among cultivar types and harvest dates on fruit water loss, firmness, and appearance. Besides more rapid loss of fruit quality, we observed that pepper fruit with high-water-loss rates generally ripened earlier than those with low water loss, another potentially unfavorable aspect of rapid water loss as it relates to fruit shelf life. Akkaravessapong et al. (1996) found that higher rates of postharvest water loss in 
Table 5. Total amounts of pepper fruit wax constituents from four pepper cultivars ('il-60', 'il-78', 'il-58', and 'il-80') determined using GC-MS after $5 \mathrm{~d}$ storage at $20^{\circ} \mathrm{C}$ and $85 \%$ relative humidity.

\begin{tabular}{ccccc}
\hline & \multicolumn{4}{c}{ Cultivar } \\
\cline { 2 - 5 } Acids, CL & il-60 & \multicolumn{4}{c}{ il-78 } & il-58 & il-80 \\
\cline { 2 - 5 } 16 & 0.03 & 0.03 & 0.04 & 0.05 \\
18 & 0.03 & 0.04 & 0.04 & 0.07 \\
20 & 0.01 & 0.02 & 0.02 & 0.05 \\
22 & 0.01 & 0.01 & 0.02 & 0.04 \\
24 & 0.03 & 0.03 & 0.03 & 0.05 \\
26 & 0.04 & 0.03 & 0.05 & 0.07 \\
28 & 0.03 & 0.02 & 0.04 & 0.04 \\
iso-Alkanes & & & & \\
iso 27 & 0.02 & 0.03 & 0.04 & 0.06 \\
iso 29 & 0.06 & 0.06 & 0.08 & 0.07 \\
iso 31 & 0.07 & 0.06 & 0.10 & 0.10 \\
iso 33 & 0.03 & 0.04 & 0.05 & 0.06 \\
-Alkanes & & & & \\
23 & 0.01 & 0.02 & 0.01 & 0.02 \\
24 & 0.01 & 0.02 & 0.01 & 0.04 \\
25 & 0.00 & 0.00 & 0.00 & 0.00 \\
26 & 0.01 & 0.02 & 0.04 & 0.06 \\
27 & 0.09 & 0.10 & 0.15 & 0.13 \\
28 & 0.02 & 0.02 & 0.05 & 0.08 \\
29 & 0.19 & 0.25 & 0.28 & 0.24 \\
30 & 0.03 & 0.03 & 0.07 & 0.08 \\
31 & 0.43 & 0.30 & 0.59 & 0.45 \\
32 & 0.02 & 0.03 & 0.06 & 0.08 \\
33 & 0.08 & 0.06 & 0.14 & 0.12 \\
Amyrins & & & & \\
$\alpha$ & 0.10 & 0.15 & 0.11 & 0.14 \\
Unknowns & 0.36 & 0.81 & 0.80 & 0.10 \\
\hline Stanyyyy & & 0.18 & 0.11 \\
\hline
\end{tabular}

Standard deviations for individual constituents (data not shown) were comparable to the associated wax class values from Table 4. ${ }^{\mathrm{z}} \mathrm{CL}$ is the carbon chain length in each wax constituent, except that $\mathrm{C}_{27}$ iso-alkanes are 2-methyl $\mathrm{C}_{26}, \mathrm{C}_{29}$ iso-alkanes are 2-methyl $\mathrm{C}_{28}, \mathrm{C}_{31}$ iso-alkanes are 2-methyl $\mathrm{C}_{30}$, and $\mathrm{C}_{33}$ iso-alkanes are 2-methyl $\mathrm{C}_{32}$ branched alkanes.

Table 6. Means of fruit fresh weight (FFW), pericarp weight (PW), pericarp surface area (PSA), fruit pericarp thickness (PT), initial water content (IWC), and dry matter content (DM) of 10 selected pepper cultivars after $5 \mathrm{~d}$ storage at $20^{\circ} \mathrm{C}$ and $85 \%$ relative humidity.

\begin{tabular}{|c|c|c|c|c|c|c|}
\hline Cultivar & $\begin{array}{c}\text { FFW } \\
(\mathrm{g})\end{array}$ & $\begin{array}{l}\text { PW } \\
(\mathrm{g})\end{array}$ & $\begin{array}{l}\text { PSA } \\
\left(\mathrm{cm}^{2}\right)\end{array}$ & $\begin{array}{l}\text { PT } \\
(\mathrm{cm})\end{array}$ & $\begin{array}{c}\text { IWC } \\
(\mathrm{g})\end{array}$ & $\begin{array}{c}\text { DM } \\
(\% \text { fresh } \\
\text { disk wt) }\end{array}$ \\
\hline il-57 & $164.49 \mathrm{~b}^{z}$ & $127.34 \mathrm{~b}$ & $0.78 \mathrm{~b}$ & $0.48 \mathrm{abc}$ & $111.45 \mathrm{~b}$ & $12.4 \mathrm{~cd}$ \\
\hline il-58 & $61.02 \mathrm{e}$ & $42.66 \mathrm{f}$ & $0.70 \mathrm{bc}$ & $0.27 \mathrm{f}$ & $36.15 \mathrm{f}$ & $15.2 \mathrm{a}$ \\
\hline il-60 & $173.69 \mathrm{~b}$ & $139.87 \mathrm{~b}$ & $0.67 \mathrm{bcd}$ & $0.53 \mathrm{a}$ & $124.07 \mathrm{~b}$ & $11.2 \mathrm{e}$ \\
\hline il-78 & $37.45 \mathrm{f}$ & $24.56 \mathrm{~g}$ & $0.54 \mathrm{~d}$ & $0.25 \mathrm{f}$ & $21.72 \mathrm{~g}$ & $11.4 \mathrm{e}$ \\
\hline il-80 & $38.60 \mathrm{f}$ & $25.31 \mathrm{~g}$ & $1.27 \mathrm{a}$ & $0.38 \mathrm{de}$ & $21.87 \mathrm{~g}$ & $13.5 \mathrm{~b}$ \\
\hline il-93 & $111.88 \mathrm{c}$ & $88.07 \mathrm{c}$ & $0.64 \mathrm{bcd}$ & $0.45 \mathrm{bc}$ & $76.65 \mathrm{c}$ & $12.9 \mathrm{bc}$ \\
\hline il-100 & $79.53 \mathrm{~d}$ & $50.80 \mathrm{e}$ & $1.16 \mathrm{a}$ & $0.43 \mathrm{~cd}$ & $43.17 \mathrm{e}$ & $15.0 \mathrm{a}$ \\
\hline il-107 & $74.94 \mathrm{~d}$ & $52.71 \mathrm{e}$ & $1.24 \mathrm{a}$ & $0.36 \mathrm{e}$ & $45.52 \mathrm{e}$ & $13.6 \mathrm{~b}$ \\
\hline il-152 & $242.33 \mathrm{a}$ & $199.53 \mathrm{a}$ & $0.61 \mathrm{~cd}$ & $0.51 \mathrm{ab}$ & $176.27 \mathrm{a}$ & $11.5 \mathrm{de}$ \\
\hline il-153 & $83.17 \mathrm{~d}$ & $62.48 \mathrm{~d}$ & $0.62 \mathrm{~cd}$ & $0.35 \mathrm{e}$ & $53.92 \mathrm{~d}$ & $13.6 \mathrm{~b}$ \\
\hline$P$ value & 0.0001 & 0.0001 & 0.0001 & 0.0001 & 0.0001 & 0.001 \\
\hline
\end{tabular}

${ }^{z}$ Values in each column not connected by the same letter are significantly different. $P \leq 0.01$, according to Tukey-Kramer honestly significant difference.
Table 7. Correlation coefficient values between water loss rate (WLR), fruit fresh weight (FFW), pericarp weight (PW), pericarp surface area (PSA), pericarp thickness (PT), initial water content (IWC), and dry matter content (DM) of 10 selected pepper cultivars after $5 \mathrm{~d}$ storage at $20^{\circ} \mathrm{C}$ and $85 \%$ relative humidity.

\begin{tabular}{lcrrrrr}
\hline & FFW & PW & PSA & PT & IWC & DM \\
\hline WLR & -0.41 & -0.41 & -0.52 & 0.01 & -0.41 & 0.51 \\
FFW & & 0.99 & 0.97 & 0.82 & 0.99 & -0.55 \\
PW & & & 0.98 & 0.81 & 0.99 & -0.57 \\
PSA & & & & 0.69 & 0.97 & -0.52 \\
PT & & & & & 0.81 & -0.39 \\
IWC & & & & & & -0.58 \\
\hline
\end{tabular}

avocado (Persea americana Mill.) fruit accelerated ripening, and altered the respiration rates in fruit. Selection and use of pepper cultivars (and other fruit) having naturally low fruit water loss rates, such as 'il-78' and 'il-152', could prolong shelf life.

The loss of cell membrane integrity is known to cause ion leakage and unrestricted movement of fluids within cellular compartments, and condition injurious to fruit. Gopalakrishna et al. (2001) found water stress caused more damage to sunflower (Helianthus annuus L.) leaf membranes than to groundnut (Arachis hypogaea L.) leaf membranes, and concluded that maintenance of membrane integrity under stress reflects broadly intrinsic tolerance. In a similar way, our results showed that membrane ion leakage varied within species, being high in pepper cultivars with high-water-loss rate ('il-80' and 'il-107' were $9.71 \%$ and $8.46 \%$, respectively) and low in cultivars with low-water-loss rate ('il-78' and 'il-152' were $5.89 \%$ and $6.91 \%$, respectively). These results suggest a strong association between membrane ion leakage and water loss rate in these pepper fruit, which is in agreement with the results of Walter et al. (1990) who found a relationship between increased weight loss and increased membrane ion leakage in cucumber (Cucumis sativus L.) fruit stored at $62 \% \mathrm{RH}$. Whether increased electrolyte leakage by stored fruit over time is due to the loss of membrane integrity associated with the breakdown of membrane structural components, such as the phospholipids, as suggested by studies of Ben-Yehoshua et al. (1983) and Lacan and Baccou (1996), requires further investigation.

Damage to cell membranes that increases ion leakage and water loss has been attributed, in part, to changes in lipoxygenase activity. Luo (1994) found that lipoxygenase activity in, and electrolyte leakage from, tomato fruit increased as ripening progressed. Gong-ChangRong et al. (2003) also reported a simultaneous increase in lipoxygenase activity and jasmonic acid content with increasing water loss in tobacco leaves. Similarly, we found high lipoxygenase activity in pepper cultivar il-107, 'il-80', and 'il-100', which exhibited high-water-loss rate, and low lipoxygenase activity in 'il-78' and 'il-152', which had lowwater-loss rate. Furthermore, high positive correlation existed between water loss rate and both cell membrane ion leakage $(0.95)$ and lipoxygenase activity (0.78) (Table 2), and also, cell membrane ion leakage correlated well with lipoxygenase activity (0.68). These findings reveal strong interrelationships among postharvest water loss, membrane ion leakage, and lipoxygenase activity in pepper fruit. Cell membrane changes leading to cell death are induced, in part, by both lipoxygenases and the reactive oxygen species that increase as fruit ripen (with the effectiveness of protective enzymes also being diminished as fruit age) (Panavas and Rubinstein, 1998; Rogiers-Suzy et al., 1998). Lipoxygenases themselves catalyze the oxygenation of polyunsaturated fatty 
acids bearing cis, cis-1,4 pentadiene structures, leading to the production of fatty acid hydroperoxides and free radicals that can damage membranes, proteins, and DNA (Siedow, 1991), and ultimately reduce fruit quality and commercial value during storage (Minguez-Mosquera, 1994). Lipoxygenase disruption of cell membranes, which separate cell components, could also result in mixing of cell contents leading to further injury. As such, cultivars with short fruit shelf life, such as 'il-80' and 'il-107', may hasten their own deterioration during storage via more rapid elevation in lipoxygenase activity following harvest.

The pepper cuticle is composed primarily of two kinds of lipid, wax and cutin, but also contains polysaccharides and other minor components. Although the cuticle is assumed to provide a hydrophobic barrier to water loss, the cultivar il-100 had a relatively high-water-loss rate (third highest) even though it had the highest total cuticle amount (Table 1). Moctezuma et al. (2003) reported that tomato fruit with antisense suppression of betagalactosidase gene (TBG6) had a much thicker cuticle and was very prone to fruit surface cracking. Likewise, the 'il-100' fruit surface with a heavy cuticle was also prone to cracking, which in this case may explain its relatively high-water-loss rate. No visible cracks were observed in other cultivars examined. Besides this observation, our data indicated no association between whole cuticle amount and water loss rate, membrane ion leakage, or lipoxygenase activity in pepper fruit (Table 2). Notwithstanding, previous reports are unclear about the role that variations in total cuticle amount and/or cuticle membrane thickness play in water loss by fruit. For example, Vega et al. (1991) found no relationship between cuticle structural features and weight loss by blueberry fruit during storage, whereas peach [Prunus persica (L.) Batsch.] fruit with thinner cuticles lost water more rapidly than fruit with thicker cuticles (Crisosto et al., 1994). When we examined the proportions of cutin monomers, their values for the representative cultivars il-60 and il-78 (low-water-loss rate), il-58 (medium-water-loss rate), and il-80 (high-water-loss rate) were similar, even though 'il-58' had a greater amount of all cutin monomers. The high cutin amount for 'il-58' likely explains, at least in part, the high total cuticle amounts recorded for 'il-58'. However, since cutin monomers were examined for a limited number of pepper genotypes (four out of 10), it is possible that additional cutin studies on larger populations of genetically diverse peppers could yet reveal important relationships.

The higher wax amounts for the gravimetric than GC-MS based methods may be explained by the fact that the GC-MS technique only allows for the quantification of the most nonpolar constituents (Tables 1 and 4). The cuticular wax composition of pepper fruit resembled that of tomato fruit waxes (Vogg et al., 2004), with $n$-alkanes being the major aliphatic constituents, amyrins being the major aromatic, and the $\mathrm{C}_{31}$ alkane the predominate individual constituent. Significant deposits of methylbranched alkanes were also present on pepper, similar as tomato fruit. Pepper cuticular wax amount determined gravimetrically in this report was associated with water loss rate $(0.63)$, cell membrane ion leakage $(0.56)$, and lipoxygenase activity $(0.50)$. Our results with pepper are in general agreement with Ristic and Jenks (2002), who indicated that a maize (Zea mays L.) line with the highest water loss rate also had the highest wax amounts. In contrast, our results are at variance with previous studies indicating that low postharvest water loss by various pepper fruit was associated with high wax amount (Banaras et al., 1988; Lownds et al., 1993; Maalekuu et al., 2003). Since most waxes are quite hydrophobic, and also assumed to function as a water barrier, it is still unclear why heavier wax loads are not always associated with lower water loss rates in fruit and other plant organs, such as was demonstrated by our study of pepper fruit.

Cultivar il-80 had 2.4-fold more total wax when quantified using gravimetric than GC-MS based methods. A possible explanation is that fruit of 'il-80' possessed greater amounts of non-GC quantifiable components in its waxes than other lines (like more polar compounds, too low or high volatility lipids, etc.). Increased polar constituents in 'il-80' fruit cuticles could provide one explanation for the higher water loss rates by ' $11-80$ ' fruit since previous studies have predicted that more polar constituents embedded in the cuticle could increase its permeability to water (Goodwin and Jenks, 2005). More detailed studies of the polar cuticle components in these pepper cultivars could shed additional light on this subject.

Even though our results for this pepper study reveal no clear association between specific wax or cutin constituents and pepper fruit water loss (except the counterintuitive observation that greater total wax amounts are associated with higher water loss rates), the role of cuticle lipids as a major influence on water loss from these fruit should not be disregarded. Instead, the exact wax and cutin characteristics described here may not be the critical factors controlling cuticle permeability. Other changes in the physico-chemical properties of the waxes found in the diffusion pathways of the cuticle membrane, in particular the molecular orientation of the waxes and their relative density of packing (Goodwin and Jenks, 2005; Riederer and Schreiber, 2001), could account for differences in water loss we observed. Further studies using combinations of more advanced physical methods like nuclear magnetic resonance spectroscopy, fourier transform infrared spectroscopy, and differential scanning calorimetry may be needed to elucidate the cuticle properties that determine cuticle permeability.

Fruit physical properties, such as fruit fresh weight, pericarp weight, pericarp surface area, pericarp thickness, initial water content, and dry matter content, were highly associated with each other, and varied significantly between pepper cultivars. All of these factors, except for pericarp thickness, were also associated with fruit water loss rate. Lownds et al. $(1993,1994)$ reported similar findings for these fruit parameters in other genotypes of pepper. As a comparison, Della-Justina et al. (1998) reported that the rate of water loss from the fruit of okra [Abelmoschus esculentus (L.) Moench.] was inversely proportional to fruit size. They noted that after $5 \mathrm{~d}$ storage, fresh weight loss was $75 \%$ greater in 6- to 9 -cm-long fruit than in $12-$ to $15-\mathrm{cm}$-long fruit. These findings are in full agreement with our results for pepper.

In summary, postharvest water loss rate in red ripe pepper fruit in storage at $20{ }^{\circ} \mathrm{C}$ and $85 \% \mathrm{RH}$ was closely associated with cultivar, cell membrane ion leakage, lipoxygenase activity, and cuticular wax amount. Cultivars displaying a low-water-loss rate had low membrane ion leakage, lipoxygenase activity, and matured and ripened later, than lines with a high-water-loss rate. In comparison, total cuticle amount, cutin monomer amount, and cutin monomer composition showed no association with water loss rate. Fruit fresh weight, pericarp weight, pericarp surface area, pericarp thickness, initial water content, and dry matter content were all highly associated with each other, and all but pericarp thickness showed moderate association with rates of fruit water loss. Our identification and description of specific factors associated with postharvest water loss in pepper fruit, such as cell membrane ion leakage, lipoxygenase activity, and cuticular wax amount, provides new insight into factors control- 
ling fruit water loss after harvest. This new understanding about fruit water loss lays important groundwork that will assist future research seeking to improve handling of commercial produce, specifically as it relates to the manipulation of factors affecting shelf life in pepper fruit.

\section{Literature Cited}

Akkaravessapong, P., L.G. Smith, D.C. Joyce, D.H. Simons, I.F. Horton, and D.R. Beasley. 1996. Increasing rates of postharvest water loss hasten ripening and alter respiration rates of avocado fruit. Proc. Austral. Postharvest Hort. Conf. Sci. Technol. Fresh Food Revolution, Melbourne, Australia, 18 Sept. 22:25-28.

Banaras, M., N.K. Lownds, and P.W. Bosland. 1988. Relationship between postharvest water loss and epicuticular wax of pepper fruits. Capsicum Nwsltr. 7:56-57.

Baur, P., H. Marzouk, and J. Schönherr. 1999. Estimation of path lengths for diffusion of organic compounds through leaf surfaces. Plant Cell Environ. 22:291-299.

Ben-Yehoshua S., B. Shapiro, Z.E. Chen, and S. Lurie. 1983. Mode of action of plastic film in extending shelf life of lemon and bell pepper fruit by alleviation of water stress. Plant Physiol. 73:87-93.

Crisosto, C.H., J.R. Scott, G. Luza-Juvenal, and G.M. Crisosto. 1994. Irrigation regimes affect fruit soluble solids concentration and rate of water loss of O'Henry peaches. HortScience 29:1169-1171.

Della-Justina, M.E., F.L. Finger, and M. Ouiatti. 1998. Postharvest loss of fresh matter and water in okras affected by fruit size and mechanical damage Revista Brasileira-de-Armazenamento 23:37-40.

Diaz-Perez, J.C. 1998. Transpiration rates in eggplant fruit as affected by fruit size and calyx size. Postharvest Biol. Technol. 13:45-49.

Ealing, P.M. 1994. Lipoxygenase activity in ripening tomato fruit pericarp tissue. Phytochemistry 36:547-552.

Eglinton, G. and D.H. Hunneman. 1968. Gas chromatographic-mass spectrometric studies of long chain hydroxyl acids. Phytochemistry 7:313-322.

El-Otmani, M. and C.W. Coggins, Jr. 1985. Fruit age and growth regulator effects on quantity and structure of the epicuticular wax of Washington navel orange fruit. J. Amer. Soc. Hort. Sci. 110:371-378.

Gong-ChangRong, Li-YanMei, Yang-LiJun, C.R. Gong, Y.M. Li, and L.J. Yang. 2003. Relationship between LOX activity, sialic acid and jasmonic acid accumulation in tobacco leaves under water stress. Agr. Sci. China 2:624-658.

Goodwin, S.M. and M.A. Jenks. 2005. The plant cuticle involvement in drought tolerance, p. 14-36. In: M.A. Jenks and P.M. Hasegawa (eds.). Plant abiotic stress. Blackwell, Oxford, U.K.

Gopalakrishna, R., Ganesh Kumar, B.T. Krishna Prasad, M.K. Mathew, and M.U. Kumar. 2001. A stress responsive gene from groundnut, Gdi-15, is homologous to flavonol 3-O-glucosyltransferase involved in anthocynin biosynthesis. Biochem. Biophys. Res. Comm. 284:574-579.

Holloway, P.J. 1982. The chemical constitution of plant cutins, p. 45-85. In: D.A. Cutler and K. Price (eds.). The plant cuticle. Linnean Soc. Symp. Series. Academic, London.

Holloway, P.J. 1984. Cutins and suberins, the polymeric plant lipids, p. 321-345. In: H.K. Mangold, G. Zweig, and J. Sherma (eds.). CRC handbook of chromatography: Lipids. vol 1. CRC Press, Boca Raton, Fla.

Jenks, M.A., H.A. Tuttle, S.D. Eigenbrode, and K.A. Feldman. 1995. Leaf epicuticular waxes of the eceriferum mutants in Arabidopsis. Plant Physiol. 108:369-377.

Jenks, M.A., L. Anderson, R. Teusink, and M. Williams. 2001. Leaf cuticular waxes of potted rose cultivarsas affected by plant development, drought, and paclobutrazol treatments. Physiol. Plant. 112:62-70.

Knowles, L., M.R. Trimble, and N.R. Knowles. 2001. Phosphorus status affects postharvest respiration, membrane permeability and lipid chemistry of European seedless cucumber fruit (Cucumis sativus L.). Postharvest Biol. Technol. 21:179-188.
Lacan, D. and J.C. Baccou. 1996. Changes in lipids and electrolytes leakage during nonnetted muskmelon ripening. J. Amer. Soc. Hort. Sci. 121:554-558.

Leopold, C., M.E. Musgrave, and M.K. Williams. 1981. Solute leakage resulting from leaf desiccation. Plant Physiol. 68:1222-1225.

Lownds, N.K., M. Banaras, and P.W. Bosland. 1993. Relationships between postharvest water loss and physical properties of pepper fruit (Capsicum annuum L.). HortScience 28:1182-1184.

Lownds, N.K., M. Banaras, and P.W. Bosland. 1994. Posthartvest water loss and storage quality of nine pepper (Capsicum) cultivars. HortScience 29:191-193.

Luo, Y. 1994. Effects of lipoxygenase on the postharvest physiology of tomato fruit. Acta Hort. Sinica 21:357-360.

Maalekuu, K., Y. Elkind, S. Tuvia-Alkalai, Y. Shalom, and E. Fallik. 2003. Quality evaluation of three sweet pepper cultivars after prolong storage. Adv. Hort. Sci. 17:187-191.

Maalekuu, K., Y. Elkind, S. Tuvia-Alkalai, Y. Shalom, and E. Fallik. 2004. The influence of harvest season and cultivar type on several quality traits and quality stability of three commercial sweet bell peppers during the harvest period. Adv. Hort. Sci. 18:21-25.

Marangoni, A.G., T. Palma, and D.W. Stanley. 1996. Membrane effects in postharvest physiology. Postharvest Biol. Technol. 7:193-217.

Minguez-Mosquera, M.I., M. Jaren-Galan, and J. Garrido-Fernandez. 1993. Lipoxygenase activity during pepper ripening and processing of paprika. Phytochemistry 32:1103-1108.

Minguez-Mosquera, M.I., J. Jaren-Galan, and J. Garrido-Fernandez. 1994. Carotenoid metabolism during the slow drying of pepper fruits of the cultivar Agridulce variety. J. Agr. Food Chem. 42:2260-2264.

Moctezuma, E., D.L. Smith, and K.C. Gross. 2003. Antisense suppression of a B-galactosidase gene (TBG6) in tomato increases fruit cracking. J. Expt. Bot. 54:2025-2033.

Norris, R.F. and M.J. Bucovac. 1968. Structure of the pear leaf cuticle with special reference to cuticular penetration. Amer. J. Bot. 55:975-983.

Panavas, T. and B. Rubinstein. 1998. Oxidative events during programmed cell death of day lily (Hemerocallis hybrid) petals. Plant Sci. Limerick. 133:125-138.

Riederer, M. and L. Schreiber. 2001. Protecting against water loss: analysis of the barrier properties of plant cuticles. J. Expt. Bot. 52:2023-2032.

Ristic, Z. and M.A. Jenks. 2002. Leaf cuticle and water loss in maize lines differing in dehydration avoidance. J. Plant Physiol. 159:645-651.

Robinson, J.E., K.M. Browne, and W.G. Burton. 1975. Storage characteristics of some vegetables and soft fruits. Ann. Appl. Biol. 81:399-408.

Rogiers-Suzy, Y., G.N.M. Kumar, and N.R. Knowles. 1998. Maturation and ripening of Amelanchier Nutt. are accompanied by increasing oxidative stress. Ann. Bot. London 81:203-211.

Sall, J., A. Lehman, and L. Creighton. 2001. JMP Start Statistics (2nd ed.). Duxbury Press, Pacific Grove, Calif.

Siedow, J.N. 1991. Plant lipoxygenase: Structure and function. Annu. Rev. Plant Physiol. Plant Mol. Biol. 42:145-188.

Vega, A., J. Luza, S. Espina, and L.A. Lizana. 1991. Characterization of the epidermis of three blueberry (Vaccinium corymbosum L.) cultivars and water loss at different storage temperatures. Proc. Interamerican Soc. Trop. Hort. 35:263-274.

Vogg, G., S. Fischer, J. Leide, E. Emmanuel, R. Jetter, A.A. Levy, and M. Riederer. 2004. Tomato fruit cuticular waxes and their effects on transpiration barrier properties: functional characterization of a mutant deficient in a very-long-chain fatty acid B-ketoacyl-CoA synthase. J. Expt. Bot. 55:1401-1410.

Walter,W.M., D.G. Epley, and R.F. Mcfeeters. 1990. Effect of water stress on stored pickling cucumbers. J. Agr. Food Chem. 38:2185-2191.

Watada, A.E, S.D. Kim, K.S. Kim, and T.C. Harris. 1987. Quality of green beans, bell peppers and spinach stored in polyethylene bags. J. Food Sci. 52:1637-1641.

Xiao, F., S.M. Goodwin, Y. Xiao, Z. Sun, D. Baker, X. Tang, M.A. Jenks, and J.M. Zhou. 2004. Arabidopsis CYP86A2 negatively regulates Pseudomonas syringae type III genes and is required for cuticle development. EMBO J. 23:2903-2913. 